\title{
Correction to: A new approach on synergistic effect and chemical stability of graphene oxide-magnetic nanocomposite in the heterogeneous Fenton degradation of caffeine
}

\author{
Manuel Alejandro Ramirez-Ubillus ${ }^{1} \cdot$ Nayara de Melo Costa-Serge ${ }^{1,2} \cdot$ Peter Hammer $^{1}$. \\ Raquel Fernandes Pupo Nogueira, ${ }^{1,2}$
}

Published online: 24 February 2022

๑) Springer-Verlag GmbH Germany, part of Springer Nature 2022

Correction to: Environmental Science and Pollution Research (2021) 28:55014-55028 https://doi.org/10.1007/s11356-021-14714-8

The original publication contains the incorrect Supplementary materials.

The correct Supplementary materials is shown in this paper.

Supplementary Information The online version contains supplementary material available at https://doi.org/10.1007/s11356-022-19344-2.

Publisher's Note Springer Nature remains neutral with regard to jurisdictional claims in published maps and institutional affiliations.

The original article can be found online at https://doi.org/10.1007/ s11356-021-14714-8.

\footnotetext{
Raquel Fernandes Pupo Nogueira raquel.pupo@unesp.br

1 Institute of Chemistry, São Paulo State University (UNESP), Araraquara, SP 14800-900, Brazil

2 UNESP, National Institute for Alternative Technologies of Detection, Toxicological Evaluation and Removal of Micropollutants and Radioactives (INCT-DATREM), Institute of Chemistry, Araraquara, SP 14800-900, Brazil
} 